\title{
Model of a double circuit with parallel cables for each phase in a HV cable connection
}

\section{Citation for published version (APA):}

Wu, L., Wouters, P. A. A. F., \& Steennis, E. F. (2012). Model of a double circuit with parallel cables for each phase in a HV cable connection. In IEEE International Conference on Power System Technology, 30 Oktober - 2 November 2012, Auckland, New Zealand (pp. 1-5). Institute of Electrical and Electronics Engineers. https://doi.org/10.1109/PowerCon.2012.6401324

DOI:

10.1109/PowerCon.2012.6401324

Document status and date:

Published: 01/01/2012

\section{Document Version:}

Publisher's PDF, also known as Version of Record (includes final page, issue and volume numbers)

\section{Please check the document version of this publication:}

- A submitted manuscript is the version of the article upon submission and before peer-review. There can be important differences between the submitted version and the official published version of record. People interested in the research are advised to contact the author for the final version of the publication, or visit the $\mathrm{DOI}$ to the publisher's website.

- The final author version and the galley proof are versions of the publication after peer review.

- The final published version features the final layout of the paper including the volume, issue and page numbers.

Link to publication

\section{General rights}

Copyright and moral rights for the publications made accessible in the public portal are retained by the authors and/or other copyright owners and it is a condition of accessing publications that users recognise and abide by the legal requirements associated with these rights.

- Users may download and print one copy of any publication from the public portal for the purpose of private study or research.

- You may not further distribute the material or use it for any profit-making activity or commercial gain

- You may freely distribute the URL identifying the publication in the public portal.

If the publication is distributed under the terms of Article 25fa of the Dutch Copyright Act, indicated by the "Taverne" license above, please follow below link for the End User Agreement:

www.tue.nl/taverne

Take down policy

If you believe that this document breaches copyright please contact us at:

openaccess@tue.nl

providing details and we will investigate your claim. 


\title{
Model of a Double Circuit with Parallel Cables for Each Phase in a HV Cable Connection
}

\author{
L. Wu, Student Member, IEEE, P.A.A.F. Wouters, and E.F. Steennis
}

\begin{abstract}
In Extra/High-Voltage (EHV/HV) power systems, power cables are chosen instead of over-head lines (OHL) at some places. In the Randstad region in the west of the Netherlands, the cable connection consists of a double circuit where each phase is connected via two parallel cables. The cables are cross-bonded every $0.9 \mathrm{~km}$. A complete model is required to efficiently analyze interaction with the remainder of the connection consisting of overhead lines. This paper presents a method to build a symbolic model of the parallel connection of multiple cables per phase in a (EHV/HV) cable system, which can be the basis of transient analysis in the frequency domain of a large transmission system containing multiple parallel conductors. The model is analyzed and compared by means of a frequency scan of the system with PSCAD/EMTDC simulation.
\end{abstract}

Index Terms--Frequency domain analysis, Power cables, Power system simulation

\section{INTRODUCTION}

$\mathrm{C}$ URRENTLY over a total length of $20 \mathrm{~km}$ HVAC power cables are planned at various places within a new $380 \mathrm{kV}$ connection in the west of the Netherlands (Randstad380 project). To match the capacity of the overhead lines to which the cables are connected, each phase consists of two cables, meaning 12 cables in total for a double circuit. In order to analyze the influence introduced by the cables to the network, models of them are required. Power system simulation software using Electromagnetic Transients Program (EMTP) theory is capable to analyze the cable numerically. A symbolic approach, if possible, allows software users to better interpret the results by the ability of conveniently varying parameter values. The symbolic solution can provide complete information helping to gain deeper knowledge about the system.

In this paper the cable model consists of one major section containing three $0.9 \mathrm{~km}$ long minor sections which are crossbonded. The screens at the ends of the major section are grounded as indicated in Fig. 1. The model of cross-bonding system can be found in [1]. The symbolic solution for a threecable three-phase system including cross-bonding system can

This work was financially supported by TenneT TSO B.V. within the framework of the Randstad 380 cable research project, Arnhem, the Netherlands.

L. Wu, P.A.A.F. Wouters, and E.F. Steennis are with Eindhoven University of Technology, P.O.Box 513, 5600 MB Eindhoven, the Netherlands (e-mail: lei.wu@tue.nl). E.F. Steennis is also with DNV KEMA Energy \& Sustainability, P.O.Box 9035, 6800 ET, Arnhem, the Netherlands.

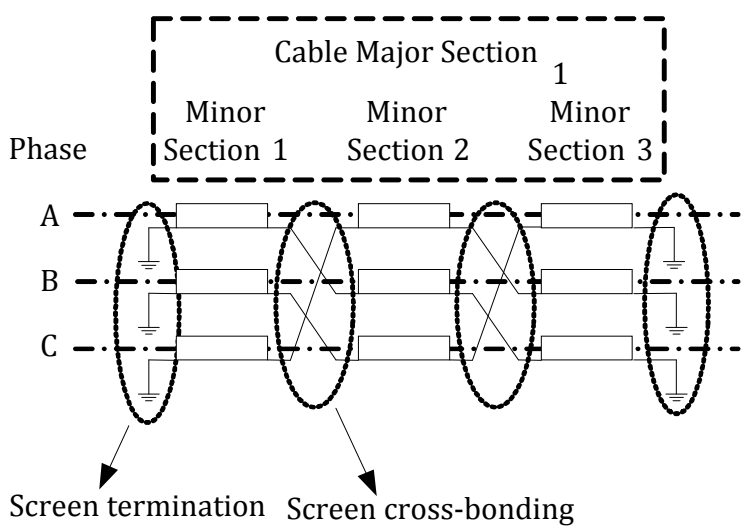

Fig. 1. Configuration of one major section with three cross-bonded minor sections.

be formulated in terms of the so-called ABCD-matrix (see [2]). The parameters involved are established in a similar way to the methods used in [3]-[6]. This paper introduces a method that supports parallel connected cables in a three-phase cable system. As demonstration of the model, a frequency scan is applied to part of the actual Randstad380 connection and the results are analyzed and compared with results from PSCAD/EMTDC simulation.

In Section II, the symbolic model of the parallel connection of any number of cables is introduced. Section III describes the symbolic method for obtaining the frequency response. In Section IV, the frequency response of a given cable system is compared with simulation

\section{Parallel Connection of Multiple Cables}

In order to have a flexible model, the parallel connection applies to an arbitrary number of parallel cables per phase. Each phase can be represented by a single input and output port, see Fig. 2; in a three-phase cable system there are three input and output ports. This section deals with the modeling of parallel connection of two or more cables. Directly applying the "parallel" information to the ABCD-matrix of a cable system will result in tedious calculations. Moreover, for different number of parallel cables, one has to specifically derive the equations for each specific situation. This complexity can be avoided by adopting the method presented in this paper. 


\section{A. N Parallel Cables per Phase}

Suppose there are in total $n$ cables in an arbitrary cable system ( $n=N$ or $n=3 N$ for a single-phase or three-phase system, respectively with $N$ is the number of cables per phase), the resulting ABCD-matrix of this system is a $2 \times n$-by$2 \times n$ matrix,

$$
\left[\begin{array}{c}
\underline{U}_{1 p} \\
\vdots \\
\underline{U}_{n p} \\
\underline{I}_{1 p} \\
\vdots \\
\underline{I}_{n p}
\end{array}\right]=\left[\begin{array}{cccccc}
\underline{A}_{11} & \cdots & \underline{A}_{1 n} & \underline{B}_{11} & \cdots & \underline{B}_{1 n} \\
\vdots & \ddots & \vdots & \vdots & \ddots & \vdots \\
\underline{A}_{n 1} & \cdots & \underline{A}_{n n} & \underline{B}_{n 1} & \cdots & \underline{B}_{n n} \\
\underline{C}_{11} & \cdots & \underline{C}_{1 n} & \underline{D}_{11} & \cdots & \underline{D}_{1 n} \\
\vdots & \ddots & \vdots & \vdots & \ddots & \vdots \\
\underline{C}_{n 1} & \cdots & \underline{C}_{n n} & \underline{D}_{n 1} & \cdots & \underline{D}_{n n}
\end{array}\right]\left[\begin{array}{c}
\underline{U}_{1 q} \\
\vdots \\
\underline{U}_{n q} \\
\underline{I}_{1 q} \\
\vdots \\
\underline{I}_{n q}
\end{array}\right]
$$

Here, the subscripts " $p$ " and " $q$ " indicate the left and right terminals, and all " $U$ " and " $\underline{P}$ " quantities are related to the conductor of the cables. Equation (1) not only can represent a single phase if all cables are parallel connected, but also can be generalized to a three-phase system. Equation (1) can be compactly written in the form

$$
\left[\begin{array}{l}
\mathbf{U}_{p} \\
\mathbf{I}_{p}
\end{array}\right]=\left[\begin{array}{ll}
\mathbf{K}_{11} & \mathbf{K}_{12} \\
\mathbf{K}_{21} & \mathbf{K}_{22}
\end{array}\right]\left[\begin{array}{l}
\mathbf{U}_{q} \\
\mathbf{I}_{q}
\end{array}\right]
$$

Rearrangement such that the current related quantities occur at the left hand side results in

$$
\left[\begin{array}{c}
\mathbf{I}_{p} \\
\mathbf{I}_{q}
\end{array}\right]=\left[\begin{array}{cc}
\mathbf{K}_{22} \mathbf{K}_{12}^{-1} & \mathbf{K}_{21}-\mathbf{K}_{22} \mathbf{K}_{12}^{-1} \mathbf{K}_{11} \\
\mathbf{K}_{12}^{-1} & -\mathbf{K}_{12}^{-1} \mathbf{K}_{11}
\end{array}\right]\left[\begin{array}{c}
\mathbf{U}_{p} \\
\mathbf{U}_{q}
\end{array}\right]
$$

The reverse rearrangement starting from

$$
\left[\begin{array}{l}
\mathbf{I}_{p} \\
\mathbf{I}_{q}
\end{array}\right]=\left[\begin{array}{ll}
\mathbf{M}_{11} & \mathbf{M}_{12} \\
\mathbf{M}_{21} & \mathbf{M}_{22}
\end{array}\right]\left[\begin{array}{l}
\mathbf{U}_{p} \\
\mathbf{U}_{q}
\end{array}\right]
$$

results in:

$$
\left[\begin{array}{c}
\mathbf{U}_{p} \\
\mathbf{I}_{p}
\end{array}\right]=\left[\begin{array}{cc}
-\mathbf{M}_{21}^{-1} \mathbf{M}_{22} & -\mathbf{M}_{21}^{-1} \\
\mathbf{M}_{12}-\mathbf{M}_{11} \mathbf{M}_{21}^{-1} \mathbf{M}_{22} & \mathbf{M}_{11} \mathbf{M}_{21}^{-1}
\end{array}\right]\left[\begin{array}{c}
\mathbf{U}_{q} \\
\mathbf{I}_{q}
\end{array}\right]
$$

Assume there are $N$ cables (in a single-phase connection $n=N$ ) and they are parallel connected, see Fig. 2.

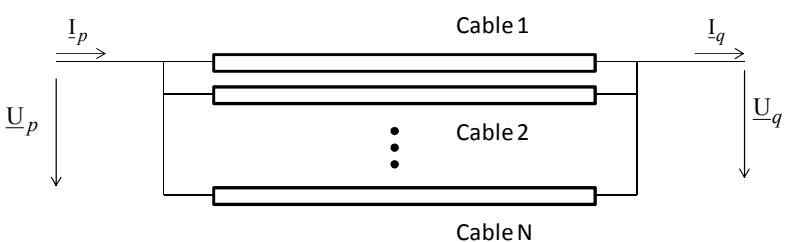

Fig. 2. Single phase with parallel connection of $N$ cables

The ABCD-matrix for $N$ cables can be written in the form of (2). The "U' and "I' quantities are column vectors, given by

$$
\begin{aligned}
\mathbf{U}_{p} & =\left[\begin{array}{lll}
U_{1 p} & \cdots & \underline{U}_{N p}
\end{array}\right]^{\mathrm{T}} \\
\mathbf{I}_{p} & =\left[\begin{array}{lll}
I_{1 p} & \cdots & \underline{I}_{N p}
\end{array}\right]^{\mathrm{T}}
\end{aligned}
$$

where each element in $\mathbf{K}$ is an $N$-by- $N$ matrix, for example for $\underline{K}_{11}$ :

$$
\mathbf{K}_{11}=\left[\begin{array}{ccc}
\underline{K}_{\mathrm{A} 11} & \cdots & \underline{K}_{\mathrm{A} 1 \mathrm{~N}} \\
\vdots & \ddots & \vdots \\
\underline{K}_{\mathrm{AN} 1} & \cdots & \underline{K}_{\mathrm{ANN}}
\end{array}\right]
$$

Rearranging this equation to the form of (3) provides the expressions for the $\mathbf{M}$ sub-matrices:

$$
\begin{aligned}
\mathbf{M}_{11} & =\left[\begin{array}{ccc}
\underline{M}_{\mathrm{A} 11} & \cdots & \underline{M}_{\mathrm{A} 1 \mathrm{~N}} \\
\vdots & \ddots & \vdots \\
\underline{M}_{\mathrm{AN} 1} & \cdots & \underline{M}_{\mathrm{ANN}}
\end{array}\right], \mathbf{M}_{12}=\left[\begin{array}{ccc}
\underline{M}_{\mathrm{B} 11} & \cdots & \underline{M}_{\mathrm{B} 1 \mathrm{~N}} \\
\vdots & \ddots & \vdots \\
\underline{M}_{\mathrm{BN} 1} & \cdots & \underline{M}_{\mathrm{BNN}}
\end{array}\right] \\
\mathbf{M}_{21} & =\left[\begin{array}{ccc}
\underline{M}_{\mathrm{C} 11} & \cdots & \underline{M}_{\mathrm{C} 1 \mathrm{~N}} \\
\vdots & \ddots & \vdots \\
\underline{M}_{\mathrm{CN} 1} & \cdots & \underline{M}_{\mathrm{CNN}}
\end{array}\right], \mathbf{M}_{22}=\left[\begin{array}{ccc}
\underline{M}_{\mathrm{D} 11} & \cdots & \underline{M}_{\mathrm{D} 1 \mathrm{~N}} \\
\vdots & \ddots & \vdots \\
\underline{M}_{\mathrm{DN} 1} & \cdots & \underline{M}_{\mathrm{DNN}}
\end{array}\right](7)
\end{aligned}
$$

resulting for every component in (4)

$$
\begin{aligned}
& \underline{I}_{1 p}=\underline{M}_{\mathrm{A} 11} \underline{U}_{1 p}+\cdots+\underline{M}_{\mathrm{A} 1 \mathrm{~N}} \underline{U}_{N p} \\
& +\underline{M}_{\mathrm{B} 11} \underline{U}_{1 q}+\cdots+\underline{M}_{\mathrm{B} 1 \mathrm{~N}} \underline{U}_{N q} \\
& \text { : } \\
& \underline{I}_{N p}=\underline{M}_{\mathrm{AN} 1} \underline{U}_{1 p}+\cdots+\underline{M}_{\mathrm{ANN}} \underline{U}_{N p} \\
& +\underline{M}_{\mathrm{BN} 1} \underline{U}_{1 q}+\cdots+\underline{M}_{\mathrm{BNN}} \underline{U}_{N q} \\
& \underline{I}_{1 q}=\underline{M}_{\mathrm{C} 11} \underline{U}_{1 p}+\cdots+\underline{M}_{\mathrm{C} 1 \mathrm{~N}} \underline{U}_{N p} \\
& +\underline{M}_{\mathrm{D} 11} \underline{U}_{1 q}+\cdots+\underline{M}_{\mathrm{D} 1 \mathrm{~N}} \underline{U}_{N q} \\
& \underline{I}_{N q}=\underline{M}_{\mathrm{CN} 1} \underline{U}_{1 p}+\cdots+\underline{M}_{\mathrm{CNN}} \underline{U}_{N p} \\
& +\underline{M}_{\mathrm{DN} 1} \underline{U}_{1 q}+\cdots+\underline{M}_{\mathrm{DNN}} \underline{U}_{N q}
\end{aligned}
$$

For a parallel connection, the following relationships hold:

$$
\begin{aligned}
& \underline{U}_{1 p}=\cdots=\underline{U}_{N p} \hat{=} \underline{U}_{p} \\
& \underline{U}_{1 q}=\cdots=\underline{U}_{N q} \hat{=} \underline{U}_{q} \\
& \underline{I}_{1 p}+\cdots+\underline{I}_{N p} \hat{=} \underline{I}_{p} \\
& \underline{I}_{1 q}+\cdots+\underline{I}_{N q} \hat{=} \underline{I}_{q}
\end{aligned}
$$

With the definitions for $\underline{U}_{p}, \underline{U}_{q}, \underline{I}_{p}$ and $\underline{I}_{q}$ above, we get

$$
\left[\begin{array}{l}
\underline{I}_{p} \\
\underline{I}_{q}
\end{array}\right]=\left[\begin{array}{ll}
\underline{M}_{\mathrm{A}} & \underline{M}_{\mathrm{B}} \\
\underline{M}_{\mathrm{C}} & \underline{M}_{\mathrm{D}}
\end{array}\right]\left[\begin{array}{l}
\underline{U}_{p} \\
\underline{U}_{q}
\end{array}\right]
$$

where the scalars $\underline{M}_{\mathrm{A}}, \underline{M}_{\mathrm{B}}, \underline{M}_{\mathrm{C}}$ and $\underline{M}_{\mathrm{D}}$ are the sums of all elements in $\mathbf{M}_{11}, \mathbf{M}_{12}, \mathbf{M}_{21}$, and $\mathbf{M}_{22}$ in (7), respectively. Combining (5) to (8) results for the final equation for the $N$ parallel cables:

$$
\left[\begin{array}{l}
\underline{U}_{p} \\
\underline{I}_{p}
\end{array}\right]=\left[\begin{array}{cc}
-\underline{M}_{\mathrm{C}}^{-1} \underline{M}_{\mathrm{D}} & -\underline{M}_{C}^{-1} \\
\underline{M}_{\mathrm{B}}-\underline{M} \mathrm{~A} \underline{M}_{C}^{-1} \underline{M}_{\mathrm{D}} & \underline{M} \mathrm{~A} \underline{M}_{C}^{-1}
\end{array}\right]\left[\begin{array}{l}
\underline{U}_{q} \\
\underline{I}_{q}
\end{array}\right]
$$

This equation can directly be generalized when considering a three-phase system (with phases A, B, and C). Each cable shown in Fig. 2 represents three cables and only the cables in the same phase are parallel connected. All " $\underline{U}$ " and " $\underline{ }$ " quantities above are replaced by 3-by-1 column vectors, for example in (6):

$$
\begin{aligned}
\underline{U}_{1 p} & =\left[\begin{array}{lll}
\underline{U}_{\mathrm{A} 1 p} & \underline{U}_{\mathrm{B} 1 p} & \underline{U}_{\mathrm{C} 1 p}
\end{array}\right]^{\mathrm{T}} \\
\underline{I}_{1 p} & =\left[\begin{array}{lll}
\underline{I}_{\mathrm{A} 1 p} & \underline{I}_{\mathrm{B} 1 p} & \underline{I}_{\mathrm{C} 1 p}
\end{array}\right]^{\mathrm{T}}
\end{aligned}
$$


Further, every element in $\mathbf{K}$ and $\mathbf{M}$, for example $\underline{M}_{\mathrm{A} 11}$ in (7), becomes a 3-by-3 sub-matrix.

\section{B. Application on Two Cables per Phase}

A cable system with e.g. two cables per phase can have different connection styles. For each style, in order to use (9), the row rearrangement in the ABCD-matrix must be applied accordingly. In Fig. 3, two options, indicated with $\alpha$ and $\beta$, are shown. The six cables are labeled with Roman numerals. For style $\alpha$, the phase order of I-III is equal to VI-IV; while for style $\beta$, the phase order of I-III is equal to IV-VI. In the following, only style $\alpha$ is considered as an example. The analysis is similar for style $\beta$.

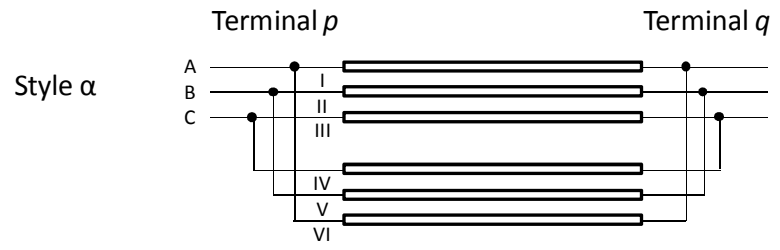

Style $\beta$

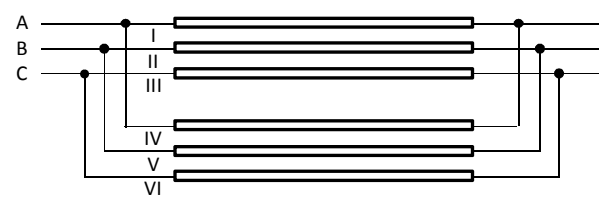

Fig. 3. Two examples of parallel connection indicated with style $\alpha$ and $\beta$

The complete model can be constructed according to the following steps.

1. Construct the matrix equation, where the $\mathrm{ABCD}$-matrix, named $\mathbf{K}$, has the form of (2).

$$
\left[\begin{array}{c}
\mathbf{U}_{1 p} \\
\mathbf{U}_{2 p} \\
\mathbf{I}_{1 p} \\
\mathbf{I}_{2 p}
\end{array}\right]=\mathbf{K}\left[\begin{array}{c}
\mathbf{U}_{1 q} \\
\mathbf{U}_{2 q} \\
\mathbf{I}_{1 q} \\
\mathbf{I}_{2 q}
\end{array}\right]
$$

The "U" and "I" quantities are 3-by-1 column vectors; the subscripts "1" and "2" indicate the two three-phase circuits respectively.

$$
\begin{aligned}
\mathbf{U}_{1 p} & =\left[\begin{array}{lll}
U_{\mathrm{I}, p} & \underline{U}_{\mathrm{II}, p} & \underline{U}_{\mathrm{III}, p}
\end{array}\right]^{\mathrm{T}} \\
\mathbf{U}_{2 p} & =\left[\begin{array}{lll}
U_{\mathrm{IV}, p} & \underline{U}_{\mathrm{V}, p} & \underline{U}_{\mathrm{VI}, p}
\end{array}\right]^{\mathrm{T}} \\
\mathbf{I}_{1 p} & =\left[\begin{array}{lll}
\underline{I}_{\mathrm{I}, p} & \underline{I}_{\mathrm{II}, p} & \underline{I}_{\mathrm{III}, p}
\end{array}\right]^{\mathrm{T}} \\
\mathbf{I}_{2 p} & =\left[\begin{array}{lll}
\underline{I}_{\mathrm{IV}, p} & \underline{I}_{\mathrm{V}, p} & \underline{I}_{\mathrm{VI}, p}
\end{array}\right]^{\mathrm{T}}
\end{aligned}
$$

2. Cables I and VI are parallel connected, as well as cable II and V, and III and IV. The rows in $\mathbf{U}_{2 p}, \mathbf{U}_{2 q}, \mathbf{I}_{2 p}$, and $\mathbf{I}_{2 q}$ must be rearranged accordingly. The row rearrangement matrix $\mathbf{R}_{\text {para }}$ can be obtained with the method described in the Appendix resulting in

$$
\left[\begin{array}{c}
\mathbf{U}_{1 p} \\
\mathbf{U}_{2 p}^{\prime} \\
\mathbf{I}_{1 p} \\
\mathbf{I}_{2 p}^{\prime}
\end{array}\right]=\mathbf{R}_{\text {para }} \mathbf{K R}_{\text {para }}^{-1}\left[\begin{array}{c}
\mathbf{U}_{1 q} \\
\mathbf{U}_{2 q}^{\prime} \\
\mathbf{I}_{1 q} \\
\mathbf{I}_{2 q}^{\prime}
\end{array}\right]
$$

where

$$
\begin{gathered}
\mathbf{U}_{2 p}^{\prime}=\left[\begin{array}{l}
\underline{U}_{\mathrm{VI}, p} \\
\underline{U}_{\mathrm{V}, p} \\
\underline{U}_{\mathrm{IV}, p}
\end{array}\right], \mathbf{U}_{2 q}^{\prime}=\left[\begin{array}{l}
\underline{U}_{\mathrm{VI}, q} \\
\underline{U}_{\mathrm{V}, q} \\
\underline{U}_{\mathrm{IV}, q}
\end{array}\right] \\
\mathbf{I}_{2 p}^{\prime}=\left[\begin{array}{l}
\underline{I}_{\mathrm{VI}, p} \\
\underline{I}_{\mathrm{V}, p} \\
\underline{I}_{\mathrm{IV}, p}
\end{array}\right], \mathbf{I}_{2 q}^{\prime}=\left[\begin{array}{l}
\underline{I}_{\mathrm{VI}, q} \\
\underline{I}_{\mathrm{V}, q} \\
\underline{I}_{\mathrm{IV}, q}
\end{array}\right]
\end{gathered}
$$

The rearrangement matrix $\mathbf{R}_{\text {para }}$ has the form

$$
\mathbf{R}_{\mathrm{para}}=\left[\begin{array}{cccc}
\text { ID } & \mathbf{O} & \mathbf{O} & \mathbf{O} \\
\mathbf{O} & \mathbf{E x} & \mathbf{O} & \mathbf{O} \\
\mathbf{O} & \mathbf{O} & \text { ID } & \mathbf{O} \\
\mathbf{O} & \mathbf{O} & \mathbf{O} & \mathbf{E x}
\end{array}\right]
$$

where ID is the 3 -by-3 identity matrix, $\mathbf{O}$ is a 3 -by-3 zero matrix, and matrix Ex is given by

$$
\mathbf{E x}=\left[\begin{array}{lll}
0 & 0 & 1 \\
0 & 1 & 0 \\
1 & 0 & 0
\end{array}\right]
$$

3. The resulting model for the six-cable system with style $\alpha$ interconnection is obtained by applying all the parallel connection modeling steps described above till (9)

$$
\left[\begin{array}{l}
\underline{U}_{A p} \\
\underline{U}_{B p} \\
\underline{U}_{C p} \\
\underline{I}_{A p} \\
\underline{I}_{B p} \\
\underline{I}_{C p}
\end{array}\right]=\left[\begin{array}{ll}
\mathbf{A} & \mathbf{B} \\
\mathbf{C} & \mathbf{D}
\end{array}\right]\left[\begin{array}{l}
\underline{U}_{A q} \\
\underline{U}_{B q} \\
\underline{U}_{C q} \\
\underline{I}_{A q} \\
\underline{I}_{B q} \\
\underline{I}_{C q}
\end{array}\right]
$$

\section{FREQUENCY SCAN ANALYSIS}

The result of (12) can be employed to make a frequency scan of the cable system. As an illustration, a three-phase load is added to the terminal $q$ of the cable, see Fig. 4.

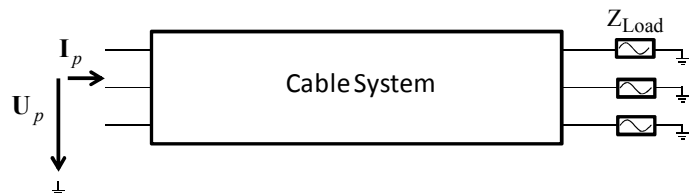

Fig. 4. Diagram for applying a frequency scan of the loaded cable system

The aim is to derive the impedance matrix $\mathbf{Z}_{p}$, which connects $\mathbf{U}_{p}$ and $\mathbf{I}_{p}$, according to

$$
\mathbf{U}_{p}=\mathbf{Z}_{p} \mathbf{I}_{p}
$$

where

$$
\begin{gathered}
\mathbf{Z}_{p}=\left[\begin{array}{lll}
\underline{\mathrm{Z}}_{\mathrm{AA}} & \underline{\mathrm{Z}}_{\mathrm{AB}} & \underline{\mathrm{Z}}_{\mathrm{AC}} \\
\underline{\mathrm{Z}}_{\mathrm{BA}} & \underline{\mathrm{Z}}_{\mathrm{BB}} & \underline{\mathrm{Z}}_{\mathrm{BC}} \\
\underline{\mathrm{Z}}_{\mathrm{CA}} & \underline{\mathrm{Z}}_{\mathrm{CB}} & \underline{\mathrm{Z}}_{\mathrm{CC}}
\end{array}\right] \\
\mathbf{U}_{p}=\left[\begin{array}{llll}
U_{\mathrm{A}} & \underline{U}_{\mathrm{B}} & \underline{U}_{\mathrm{C}}
\end{array}\right]^{\mathrm{T}}, \quad \mathbf{I}_{p}=\left[\begin{array}{lll}
\underline{I}_{\mathrm{A}} & \underline{I}_{\mathrm{B}} & \underline{I}_{\mathrm{C}}
\end{array}\right]^{\mathrm{T}}
\end{gathered}
$$

Suppose the ABCD-matrix has the form of (12), being 


$$
\left[\begin{array}{l}
\mathbf{U}_{p} \\
\mathbf{I}_{p}
\end{array}\right]=\left[\begin{array}{ll}
\mathbf{A} & \mathbf{B} \\
\mathbf{C} & \mathbf{D}
\end{array}\right]\left[\begin{array}{l}
\mathbf{U}_{q} \\
\mathbf{I}_{q}
\end{array}\right]
$$

with the load equation $\mathbf{U}_{q}=\mathbf{Z}_{\text {Load }} \mathbf{I}_{q}$. According to Fig. 4, the load impedance matrix becomes

$$
\mathbf{Z}_{\text {Load }}=\left[\begin{array}{ccc}
\underline{Z}_{\text {Load,A }} & 0 & 0 \\
0 & \underline{Z}_{\text {Load,B }} & 0 \\
0 & 0 & \underline{Z}_{\text {Load,C }}
\end{array}\right]
$$

since the load is composed of three individual impedances. Equation (13) can be rewritten as:

$$
\begin{aligned}
\mathbf{U}_{p} & =\left(\mathbf{A} \cdot \mathbf{Z}_{\mathrm{Load}}+\mathbf{B}\right) \cdot \mathbf{I}_{q} \\
\mathbf{I}_{p} & =\left(\mathbf{C} \cdot \mathbf{Z}_{\mathrm{Load}}+\mathbf{D}\right) \cdot \mathbf{I}_{q}
\end{aligned}
$$

Solving the above two equations gives the relationship between $\mathbf{U}_{p}$ and $\mathbf{I}_{p}$ :

$$
\mathbf{U}_{p}=\left(\mathbf{A} \cdot \mathbf{Z}_{\mathrm{Load}}+\mathbf{B}\right) \cdot\left(\mathbf{C} \cdot \mathbf{Z}_{\mathrm{Load}}+\mathbf{D}\right)^{-1} \cdot \mathbf{I}_{p}
$$

Comparing it with $\mathbf{U}_{p}=\mathbf{Z}_{p} \mathbf{I}_{p}$ produces the $\mathbf{Z}_{p}$ matrix

$$
\mathbf{Z}_{p}=\left(\mathbf{A} \cdot \mathbf{Z}_{\text {Load }}+\mathbf{B}\right) \cdot\left(\mathbf{C} \cdot \mathbf{Z}_{\text {Load }}+\mathbf{D}\right)^{-1}
$$

The frequency dependency of $\mathbf{Z}_{p}$ can be plotted by scanning the frequency $f$, and calculating the corresponding magnitudes of $\mathbf{Z}_{p}$. Note that $\mathbf{Z}_{p}$ is a diagonal symmetrical matrix [4],

$$
\underline{Z}_{\mathrm{AB}}=\underline{Z}_{\mathrm{BA}}, \underline{Z}_{\mathrm{BC}}=\underline{Z}_{\mathrm{CB}}, \underline{Z}_{\mathrm{AC}}=\underline{Z}_{\mathrm{CA}} \text {. }
$$

\section{FREQUENCY SCAN EXAMPLE}

The method described in Sections II and III is applied to generate a frequency scan for the cable connection indicated in Fig. 4 with two cables per phase connected according Fig. 3, style $\alpha$. The result is compared with simulations generated from PSCAD/EMTDC software. The parameters used in the model are summarized in Table I; the specific cable parameters (Fig. 5) are included in Table II. The chosen load is only meant to generate an exemplary cable system to allow a comparison with the simulations.

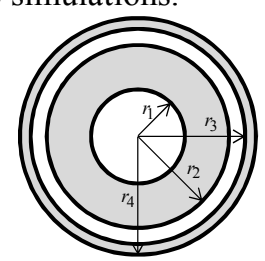

Fig. 5. Cable radii, $r_{1}$ : conductor, $r_{2}-r_{1}$ : insulation, $r_{3}-r_{2}$ : conductive screen, $r_{4}-r_{3}$ : outer sheath

The result is shown in Fig. 6, where the frequency is varied from $1 \mathrm{~Hz}$ to $10 \mathrm{kHz}$ (increment steps of $1 \mathrm{~Hz}$ ). In this figure, only the lower-left part including the main diagonal elements of matrix $\mathbf{Z}_{p}$ is shown because of its symmetry. The resulting values of $\mathbf{Z}_{p}$ (rounded numbers) at resonant frequency (289 $\mathrm{Hz}$ ) are

$$
\mathbf{Z}_{p}(289 \mathrm{~Hz})=\left[\begin{array}{ccc}
220 & 16 & 37 \\
16 & 202 & 19 \\
37 & 19 & 223
\end{array}\right]
$$

while at power frequency $(50 \mathrm{~Hz})$ the values are

$$
\mathbf{Z}_{p}(50 \mathrm{~Hz})=\left[\begin{array}{ccc}
82.9 & 0.1 & 0.1 \\
0.1 & 82.9 & 0.1 \\
0.1 & 0.1 & 83.0
\end{array}\right]
$$

This cable system is also simulated in PSCAD/EMTDC, where the same impedance is calculated, named as $\mathbf{Z}_{\mathrm{PSCAD}}$. The deviation between the result of the model in this paper and the simulation result is calculated according to

$$
\text { Error }=\left(\mathbf{Z}_{\mathrm{PSCAD}}-\mathbf{Z}_{p}\right) / \mathbf{Z}_{\mathrm{PSCAD}} \times 100 \%
$$

The deviation is plotted in Fig. 7. In the frequency range taken from 1 to $10 \mathrm{kHz}$ the deviation is virtually absent.

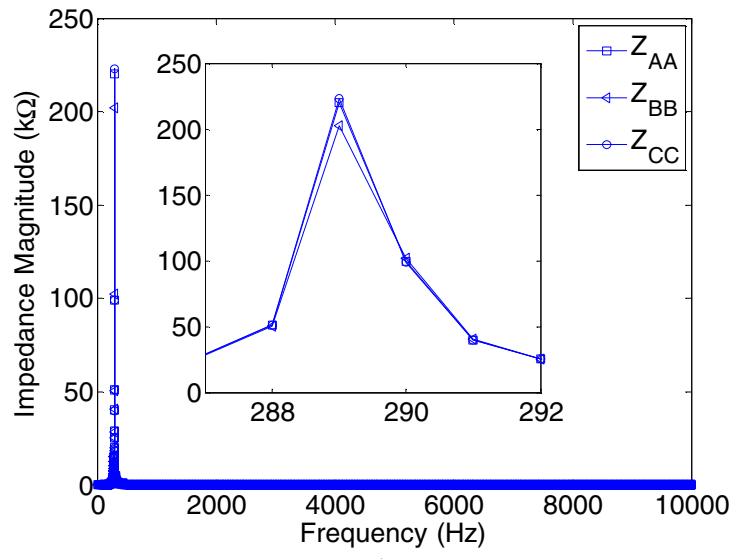

a)

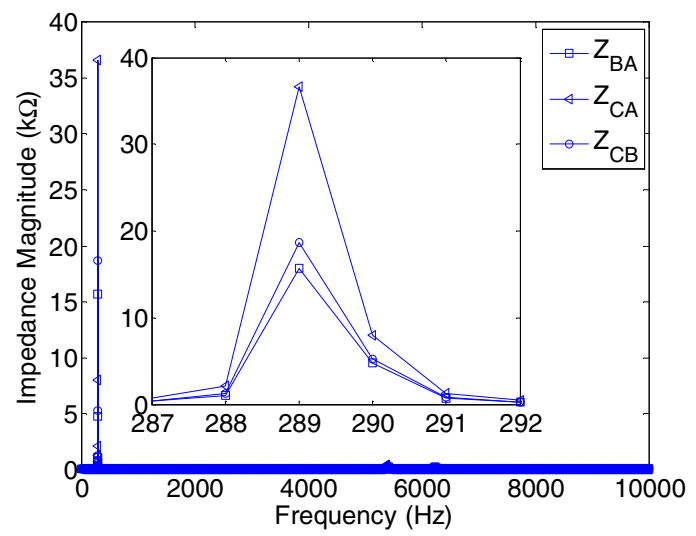

b)

Fig. 6. Frequency scan, with zoomed-in curves shown as insets: a) Main diagonal elements, b) Off diagonal elements

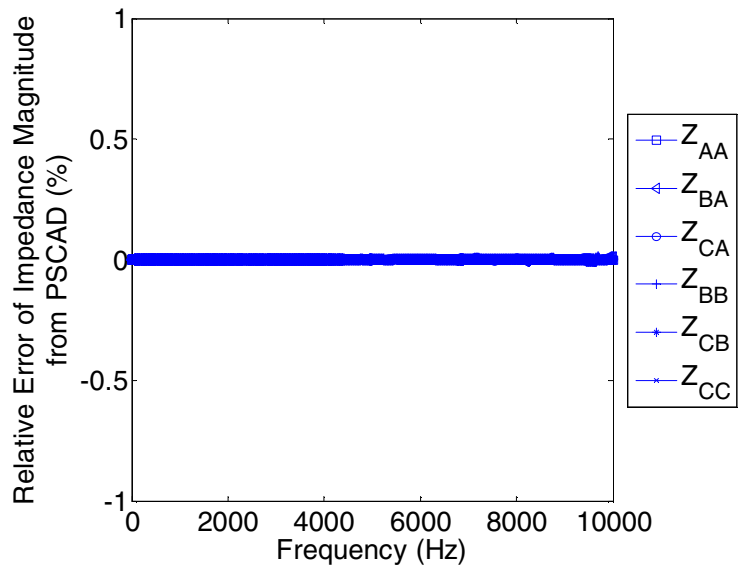

Fig. 7. Relative error for the results shown in Fig. 4 of the cable model compared with the result from PSCAD/EMTDC 
TABLE I

INPUT DATA FOR FREQUENCY SCAN OF THE CABLE SYSTEM

\begin{tabular}{|c|c|c|c|}
\hline Nominal Voltage $(\mathrm{kV})$ & 380 & Cable Depth $(\mathrm{m})^{*}$ & 1.25 \\
\hline $\begin{array}{c}\text { Cable Minor Section } \\
\text { Length }(\mathrm{km})\end{array}$ & 0.9 & $\begin{array}{c}\text { Cable Distance } \\
(\mathrm{m})^{*}\end{array}$ & 0.6 \\
\hline Earth Resistivity $(\Omega \mathrm{m})$ & 100 & $\operatorname{Load}(\mathrm{H})^{* *}$ & 0.255 \\
\hline \multicolumn{2}{|c|}{ Earth Return Approximation } & \multicolumn{2}{|l|}{ Saad [6] } \\
\hline \multicolumn{2}{|c|}{ Number of Minor Sections } & \multicolumn{2}{|l|}{3} \\
\hline
\end{tabular}

\section{CONCLUSION}

A method of modeling parallel connection of several cables applied in each phase is introduced. The method is applied to a three-phase double-cable-per-phase system in order to demonstrate the application of the model, and in addition, to validate it by comparing the result with that from PSCAD/EMTDC software. This symbolic approach gives the same result, but is more flexible and efficient in terms of computation time when studying the effect of varying input parameters. This is specifically relevant when considering more complicated networks, e.g. having 12 cables (four cables per phase) together with several major sections with crossbonded minor sections and combining the cable model with overhead lines.

\section{APPENDIX}

This section describes the row rearrangement of a matrix equation employed in Section II. The row rearrangement of a matrix or vector can be realized by multiplying with a matrix which takes care of exchanging two or more rows. For an $n$ by- $n$ matrix $\mathbf{K}$,

$$
\mathbf{K}=\left[\begin{array}{ccccc}
\vdots & \vdots & \vdots & \vdots & \vdots \\
\cdots & \cdots & a & \cdots & \cdots \\
\vdots & \vdots & \vdots & \vdots & \vdots \\
\cdots & \cdots & b & \cdots & \cdots \\
\vdots & \vdots & \vdots & \vdots & \vdots
\end{array}\right]
$$

exchanging of rows $a$ and $b$ is achieved by left multiplication with matrix $\mathbf{R}$ which equals the identity matrix with exchanged rows $a$ and $b$ :

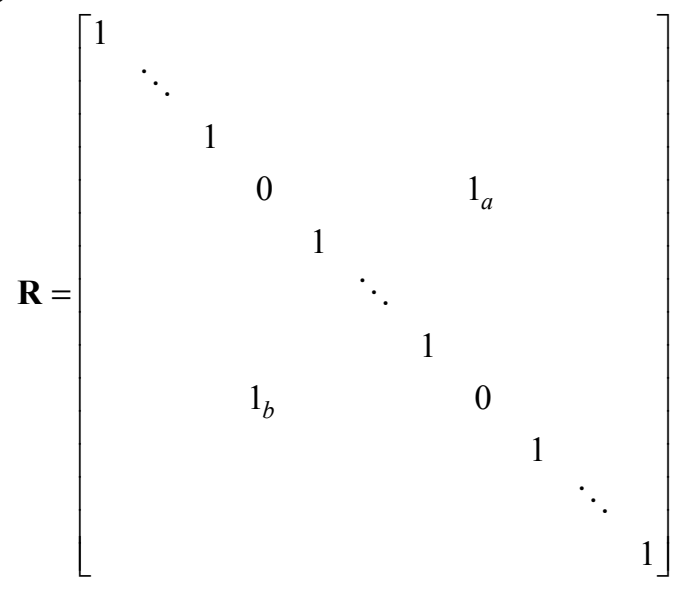

TABLE II

INPUT OF CABLE CROSS-SECTIONAL MODEL (REFERING TO FIG. 5)

\begin{tabular}{|c|c|c|c|c|}
\hline Layer & $\mathbf{1}$ & $\mathbf{2}$ & $\mathbf{3}$ & $\mathbf{4}$ \\
\hline Radius $(\mathrm{mm})$ & 30.65 & 60.35 & 62.76 & 67.86 \\
\hline Resistivity $(\Omega \mathrm{m})$ & $2.04 \times 10^{-8}$ & - & $7.32 \times 10^{-8}$ & - \\
\hline $\begin{array}{c}\text { Relative } \\
\text { Permeability }\end{array}$ & 1 & 1 & 1 & 1 \\
\hline $\begin{array}{c}\text { Relative } \\
\text { Permittivity }\end{array}$ & - & 2.67 & - & 2.3 \\
\hline
\end{tabular}

The rows in $\mathbf{K}$ are exchanged via

$$
\left[\begin{array}{ccccc}
\vdots & \vdots & \vdots & \vdots & \vdots \\
\cdots & \cdots & b & \cdots & \cdots \\
\vdots & \vdots & \vdots & \vdots & \vdots \\
\cdots & \cdots & a & \cdots & \cdots \\
\vdots & \vdots & \vdots & \vdots & \vdots
\end{array}\right]=\mathbf{R}\left[\begin{array}{ccccc}
\vdots & \vdots & \vdots & \vdots & \vdots \\
\cdots & \cdots & a & \cdots & \cdots \\
\vdots & \vdots & \vdots & \vdots & \vdots \\
\cdots & \cdots & b & \cdots & \cdots \\
\vdots & \vdots & \vdots & \vdots & \vdots
\end{array}\right]
$$

Applying the transformation to a matrix equation,

$$
\mathbf{P}=\mathbf{K} \mathbf{Q}
$$

where $\mathbf{P}$ and $\mathbf{Q}$ are both $n$-by-1 vectors

$$
\begin{aligned}
& \mathbf{P}=\left[\begin{array}{lllll}
\cdots & p_{a} & \cdots & p_{b} & \cdots
\end{array}\right]^{\mathrm{T}} \\
& \mathbf{Q}=\left[\begin{array}{lllll}
\cdots & q_{a} & \cdots & q_{b} & \cdots
\end{array}\right]^{\mathrm{T}}
\end{aligned}
$$

results in

$$
\mathbf{R P}=\mathbf{R K Q}=\left(\mathbf{R K R} \mathbf{R}^{-1}\right) \mathbf{R Q},
$$

i.e.

$$
\left[\begin{array}{c}
\vdots \\
p_{b} \\
\vdots \\
p_{a} \\
\vdots
\end{array}\right]=\mathbf{R K R}^{-1}\left[\begin{array}{c}
\vdots \\
q_{b} \\
\vdots \\
q_{a} \\
\vdots
\end{array}\right] \equiv \mathbf{M}\left[\begin{array}{c}
\vdots \\
q_{b} \\
\vdots \\
q_{a} \\
\vdots
\end{array}\right]
$$

This results in the transformation employed in (11), in Section II.

$$
\begin{gathered}
\text { M }=\mathbf{R K R}^{-1} \\
\text { VII. REFERENCES }
\end{gathered}
$$

\section{REFERENCES}

[1] U.S. Gudmundsdottir, B. Gustavsen, C.L. Bak, W. Wiechowski, "Field Test and Simulation of a 400-kV Cross-Bonded Cable System," IEEE Transactions on Power Delivery, vol.26, no.3, pp.1403-1410, July 2011.

[2] P.L.D. Peres, I.S. Bonatti, A. Lopes, Transmission Line Modeling: A Circuit Theory Approach, Society for Industrial and Applied Mathematics, vol.40, No.2, pp.347-352, June 1998.

[3] A. Ametani, "A General Formulation of Impedance and Admittance of Cables," IEEE Transactions on Power Apparatus and Systems,, vol.PAS-99, no.3, pp.902-910, May 1980.

[4] Monitoba HVDC Research Centre, EMTDC User's Guide, version 4.7, fifth printing, February 2010.

[5] L.M. Wedepohl, D.J. Wilcox, "Transient analysis of underground power-transmission systems. System-model and wave-propagation characteristics," Proceedings of the Institution of Electrical Engineers, vol.120, no.2, pp.253-260, February 1973.

[6] O. Saad, G. Gaba, M. Giroux, "A closed-form approximation for ground return impedance of underground cables," IEEE Transactions on Power Delivery, vol.11, no.3, pp.1536-1545, July 1996. 